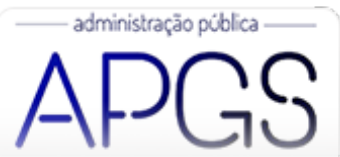

Administração Pública e Gestão Social ISSN: 2175-5787

apgs@ufv.br

Universidade Federal de Viçosa

Brasil

\title{
Job Crafting na Administração Pública: Estudo em uma Instituição Federal de Ensino no Rio de Janeiro
}

Miranda Teixeira, Luciana; de Sá Affonso da Costa, Isabel

Job Crafting na Administração Pública: Estudo em uma Instituição Federal de Ensino no Rio de Janeiro

Administração Pública e Gestão Social, vol. 13, núm. 2, 2021

Universidade Federal de Viçosa, Brasil

Disponible en: http://www.redalyc.org/articulo.oa?id=351566014004

\section{(c) $(1) \Theta \theta$}

Esta obra está bajo una Licencia Creative Commons Atribución-NoComercial-SinDerivar 3.0 Internacional. 


\title{
Job Crafting na Administração Pública: Estudo em uma Instituição Federal de Ensino no Rio de Janeiro
}

\author{
Job Crafting in Public Administration: A study at a Federal Educational Institution in Rio de Janeiro \\ Job Crafting en la Administración Pública: Estudio en una Institución Federal de Educación en Río de Janeiro
}

\author{
Luciana Miranda Teixeira \\ Redalyc: http://www.redalyc.org/articulo.oa? \\ CEFET - RJ, Brasil \\ $\mathrm{id}=351566014004$
}

luciana_mite@hotmail.com

Isabel de Sá Affonso da Costa

Escola de Negócios e Seguros - ENS, Brasil

isabelsaacosta@hotmail.com

Recepción: 19 Febrero 2020

Aprobación: 24 Junio 2020

Publicación: 01 Abril 2021

\section{Resumo:}

Objetivo da pesquisa: analisar a relação entre o processo de job crafting e o engajamento no trabalho no contexto da administração pública brasileira.

Enquadramento teórico: modelo Job Demands-Resources (JD-R) e suas dimensões: recursos, job crafting (alterações nas tarefas, nas relações no trabalho e nos aspectos cognitivos do trabalho), engajamento no trabalho.

Metodologia: coleta de evidências via triangulação de entrevistas semiestruturadas e técnica de complemento de frases junto a 12 servidores técnico-administrativos do Centro Federal de Educação Tecnológica do Rio de Janeiro (Cefet/RJ), além de análise documental. Análise e interpretação dos dados por análise de conteúdo, com grade fechada baseada nas dimensões do modelo JD-R. Resultados: os servidores possuem recursos pessoais e de trabalho; há baixa demanda de trabalho; os servidores procuram realizar alterações nas suas tarefas, relacionamentos e aspectos cognitivos do trabalho, porém essas alterações melhoram o engajamento apenas nas dimensões absorção e dedicação ao trabalho, não sendo identificada a dimensão vigor do engajamento no trabalho. Aspectos da burocracia dificultam o job crafting, mas é possível implementar práticas para incentivá-lo.

Originalidade: o job crafting e o modelo JD-R vêm ganhando espaço significativo nas pesquisas internacionais, mas são ainda muito pouco estudados no Brasil, especialmente no contexto das organizações públicas.

Contribuições teóricas e práticas: a profusão de regras internas e a centralização das decisões têm impacto mais negativo na relação entre job crafting e engajamento do que a legislação e rotina de trabalho características do serviço público. Servidores atuando na área-fim são mais propensos a procurar melhorar o engajamento através do job crafting do que os da área-meio, por possuírem maior facilidade de enxergar seu trabalho como parte de um todo integrado e por ocuparem cargos com mais elementos que favorecem a motivação, como autonomia, feedback e significância das tarefas - aspectos que apontam para a necessidade de atuação mais efetiva sobre a gestão de pessoas pelos gestores e a área de recursos humanos $(\mathrm{RH})$.

Palavras-CHaVE: Job crafting, Engajamento no trabalho, Modelo Job Demands-Resources (JD-R), Gestão de pessoas.

\section{ABstract:}

Research objective: The objective of this paper is to analyze the relationship between the job crafting process and the engagement at work in the context of the Brazilian public administration.

Theoretical framework: Job Demands-Resources (JD-R) model and its dimensions: resources, job crafting (changes in tasks, work relationships and cognitive aspects of work), work engagement.

Methodology: Evidence was collected through triangulation of semi-structured interviews and sentence completion technique with 12 servers from Cefet RJ (Federal Center for Technological Education of Rio de Janeiro), and document analysis. Analysis and interpretation of data were made through content analysis, with categories based on the dimensions of the JD-R model.

Results: Servers have personal and work resources; there is low work demand; servers seek to make changes in their tasks, relationships and cognitive aspects of work, however, these changes improve engagement only in the dimensions of absorption and dedication to work, the dimension of vigor at work was not identified. Aspects of bureaucracy may hinder job crafting, but it is possible to implement practices to foster it. 
Originality: Job crafting and the JD-R model are growing in international research, but are still understudied in Brazil, especially in the context of public organizations.

Theoretical and practical contributions: The profusion of internal rules and the centralization of decisions have a more negative impact in relation to job crafting-engagement relation than legislation and work routine characteristic of public administration. Servers working in the end area are more likely to seek to improve engagement through job crafting than those in the middle area, because it is easier for them to see their work as part of an integrated whole, and because they occupy positions with more elements that favor motivation, such as autonomy, feedback and task significance - aspects that point to the need for more effective action on people management by managers and by the human resources area.

KEYWORDS: Job crafting, Work engagement, Job Demands-Resources (JD-R) Model, People management.

\section{ReSUMEN:}

Objetivo: analizar la relación entre el proceso de job crafting y el envolvimiento en el trabajo en el contexto de la administración pública brasileña.

Encuadramiento teórico: Modelo Job Demands-Resources (JD-R) y sus dimensiones: recursos, job crafting (cambios en las tareas, en las relaciones en el trabajo y en los aspectos cognitivos del trabajo), envolvimiento.

Metodología: coleta de evidencias por triangulación de entrevistas semiestructuradas y complementación de frases con 12 servidores del Centro Federal de Educación Tecnológica de Río de Janeiro (Cefet/RJ), a demás de análisis documental. La análisis y interpretación de los datos fueran por análisis de contenido con categorías definidas a priori, basadas en las dimensiones del JD-R. Resultados: los servidores tienen recursos personales y laborales; hay poca demanda de trabajo; buscan hacer cambios en sus tareas, relaciones y aspectos cognitivos del trabajo, pero estos cambios mejoran el envolvimiento solo en las dimensiones absorción y dedicación al trabajo, no siendo identificada la dimensión vigor del envolvimiento. Aspectos de la burocracia dificultan el job crafting, pero es posible alentarlo.

Originalidad: el job crafting y el modelo JD-R han ganado espacio significativo en la investigación internacional, pero aún son poco estudiados en Brasil, especialmente en las organizaciones públicas.

Aportes teóricos y prácticos: la profusión de normas internas y la centralización de decisiones tienen un impacto más negativo en la relación entre el job craftingy el envolvimiento que la legislación y la rutina de trabajo características del servicio público. Los servidores que trabajan en el área final tienen más probabilidades de buscar mejorar el envolvimiento mediante el job crafting que los del área intermedia, porque es más fácil para ellos ver su trabajo como parte de un todo integrado y porque ocupan puestos con más elementos que favorecen la motivación, como la autonomía, la retroalimentación y la relevancia de la tarea, aspectos que apuntan a la necesidad de una acción más efectiva en la gestión de personas.

Palabras Clave: Job crafting, Envolvimiento, Modelo Job Demands-Resources (JD-R), Gestión de personas.

\section{INTRODUÇÃO}

Ao longo das últimas décadas, as mudanças econômicas e tecnológicas têm trazido importantes implicações para o trabalho dos indivíduos em todo o mundo. $\mathrm{O}$ aumento da complexidade do trabalho e a necessidade de os indivíduos desenvolverem habilidades associadas à autogestão e à iniciativa faz com que a atenção à gestão de pessoas seja crescente em organizações públicas e privadas (Boon, Eckardt, Lepak, \& Boselie, 2018; Longo, 2007; World Economic Forum [WEF], 2018). Nos estudos acadêmicos, novos construtos e teorias são propostos, visando compreender a interação entre os indivíduos e o trabalho.

$\mathrm{Na}$ administração pública brasileira, apesar da introdução de novos modelos de gestão de pessoas, a uniformidade e a padronização que caracterizam os sistemas de gestão de recursos humanos do modelo burocrático ainda são presentes. Como resultado, a organização do trabalho ainda é engessada, há excesso de especificação nas tarefas e o coletivismo nas relações laborais sobrepõe-se às demandas crescentes de segmentação e personalização das práticas de gestão de pessoal (Longo, 2007). Também a baixa autonomia, a falta de recursos materiais e humanos e a falta de recompensas pelo desempenho geram desmotivação e insatisfação no trabalho.

No contexto contemporâneo, em que o fator humano tem reconhecido seu papel central no alcance de resultados, as organizações são confrontadas com a questão de como melhorar não somente o desempenho, mas o engajamento e os estados psicológicos positivos em relação ao trabalho (Devotto \& Machado, 2017). 
Assim, contructos que permitam a compreensão de fenômenos subjetivos e intersubjetivos, tais como o engajamento, a satisfação e o sentido do trabalho, bem como suas interações, mostram-se promissores.

Nessa linha, o conceito de job crafting, proposto por Wrzesniewski e Dutton (2001), vem ganhando espaço nas pesquisas relacionadas ao comportamento organizacional. $\mathrm{O}$ job crafting busca "capturar as diferentes ações informais dos trabalhadores para moldar e redefinir seus trabalhos, alterando limites e fronteiras, de forma a alinhá-los a seus interesses e valores" (Devotto \& Machado, 2017, p. 413). O job crafting propõe que os funcionários podem realizar ativamente mudanças nos limites físicos, relacionais e cognitivos de suas tarefas para atribuir um novo significado e aumentar sua satisfação no trabalho (Wrzesniewski \& Dutton, 2001).

O Brasil vive uma complexa conjuntura econômica, que teve início com a crise econômica mundial em 2008 e agravada a partir de 2013, quando foram necessárias medidas de ajuste fiscal para equilibrar as contas do país (Mancebo, 2017). Essa crise, combinada com a expansão qualitativa e quantitativa da demanda por serviços públicos, desencadeia movimentos de mudanças inclinadas ao ajuste e à economia de recursos e geram desafios crescentes (Mancebo, 2017). Essa conjuntura afetou as instituições federais, incluindo as Instituições de Ensino Superior (IES), onde ocorreram cortes significativos de orçamento que atingiram a estrutura física e acarretaram enxugamento das funções que não fossem ligadas diretamente às atividades-fim (Mancebo, Silva, \& Oliveira, 2018).

Nesse contexto de crise e de redução de orçamento - especialmente para despesas correntes e infraestrutura - surgem indagações sobre o que os servidores fazem para criar seus próprios recursos e melhorar o seu engajamento no trabalho, caracterizando o comportamento de job crafting. Esse comportamento na administração pública representaria um avanço em direção ao modelo gerencial, que apoia a flexibilidade e a priorização dos resultados.

O objetivo deste estudo é compreender a relação entre o processo de job crafting e o engajamento no trabalho dos servidores técnico-administrativos (TAEs) do Campus Maria da Graça do Centro de Federal de Educação Tecnológica do Rio de Janeiro (CEFET/RJ), com base no modelo teórico Job Demands-Resources (JD-R). O CEFET Maria da Graça é uma unidade descentralizada (UNED) do CEFET/RJ inaugurada em 2006. A instituição é reconhecida pelo ensino público de qualidade e encontra-se em um período de expansão devido à meta institucional de transformação de Centro em Universidade Tecnológica. Ao compreender a relação entre o processo de job crafting e engajamento no trabalho de seus servidores, pretende-se contribuir com evidências que sustentem o desenvolvimento de políticas e práticas de gestão que incentivem esse comportamento nos servidores.

Este estudo torna-se relevante na medida em que também pretende contribuir para o conhecimento do constructo do job crafting e de sua relação com engajamen to no trabalho pelas organizações públicas e privadas brasileiras, visto que evidências de pesquisas, especialmente internacionais (Bakker, 2015; Cullinane, Bosak, Flood, \& Demerouti, 2017; Wingerden, Bakker, \& Derks, 2017) têm apontado impactos positivos dessa relação no trabalho. Ademais, a pesquisa inova ao analisar o job crafting sob a ótica qualitativa, por meio da adaptação de ferramenta quantitativa - escala job crafting (Tims, Bakker, \& Derks, 2012).

\section{REFERENCIAL TEÓRICO}

\subsection{Job crafting}

O conceito de job crafting foi proposto por Wrzesniewski e Dutton (2001) e refere-se às mudanças físicas e cognitivas que indivíduos fazem nos limites da tarefa e das relações no trabalho. O job crafting representa ainda as mudanças proativas que os funcionários fazem em suas demandas e recursos de trabalho (Tims et al., 2012). 
Mesmo os trabalhos mais rotineiros e restritos podem ser influenciados pelos funcionários que ativamente desempenham mudanças nas tarefas e relações que compõem o trabalho. Dessa forma, os trabalhos com baixa autonomia, autoridade e complexidade também podem ser alterados por esses funcionários, que utilizam o feedback dessas alterações para motivar ainda mais o processo de job crafting (Wrzesniewski \& Dutton, 2001).

O job crafting é principalmente uma atividade de nível individual, em que o empregado decide como e quando moldar suas tarefas e interações. $\mathrm{O}$ constructo visa a apreender os ajustes informais realizados proativamente "de baixo para cima" pelos empregados, para moldar e redefinir o trabalho através da alteração de suas fronteiras, de forma a alinhá-lo às suas preferências e interesses (Devotto \& Machado, 2017).

O efeito dessas mudanças nos aspectos cognitivos, nas tarefas ou relações é a alteração do significado e da identidade do trabalho pelos empregados. A significação do trabalho está associada a benefícios a ele relacionados, como aumento da satisfação, motivação e desempenho (Berg, Dutton, \& Wrzesniewski, 2013). A identidade do trabalho é a forma como os indivíduos se definem e a forma como descrevem os atributos e a concepção mais holística que têm de si no trabalho (Wrzesniewski \& Dutton, 2001).

O job crafting é um ato psicológico, social e físico no qual os indivíduos "criam" um trabalho diferente para si, dentro de um contexto de trabalho definido através de um processo criativo e improvisado. Isso significa que ele não é necessariamente bom ou ruim para a organização, mas depende do contexto. Ao mesmo tempo em que funcionários podem envolver-se em práticas que introduzem a inovação nos relacionamentos e tarefas, beneficiando a organização, podem colocá-la em risco devido a problemas legais ou regulamentares que comprometem o bom trabalho (Wrzesniewski \& Dutton, 2001).

Wrzesniewski e Dutton (2001) comparam o job crafting com perspectivas teóricas similares, como o job design (Hackman \& Oldham, 1980). No job design as características do trabalho, como feedback, autonomia, variabilidade de habilidades, significância e identidade das tarefas, provocam estados psicológicos críticos que visam a favorecer a motivação no trabalho. No job design os gestores alteram a motivação, a satisfação e autonomia dos funcionários mudando a complexidade da tarefa - ou seja, restringe as ações dos indivíduos a comportamentos reativos e de resolução de problemas e não desenvolvem o papel individual nas mudanças, muitas vezes focando apenas o papel dos gerentes.

No comportamento de job crafting, embora este parta do próprio indivíduo, os gestores têm influência no contexto do trabalho, que pode encorajar ou desencorajar as pessoas a alterarem os limites de suas tarefas e os limites relacionais no trabalho. Quando os gestores possibilitam a participação de funcionários nos objetivos estratégicos da organização, podem motivar o comportamento de job crafting, que pode produzir benefícios tangíveis e intangíveis tanto ao funcionário como à organização (Wrzesniewski \& Dutton, 2001).

A motivação individual para o job crafting surge de três necessidades individuais: autocontrole, imagem positiva de si mesmo e conexão com outras pessoas. A oportunidade percebida para o job crafting é definida por Wrzesniewski \& Dutton (2001) como sentimento de liberdade e discricionariedade que os indivíduos têm no trabalho. Isso significa que postos de trabalho caracterizados por elevada autonomia de trabalho e baixa interdependência entre tarefas são mais propensos à ocorrência do comportamento de job crafting (Cullinane et al., 2017).

Ojob crafting pode alterar os limites do trabalho a partir de três técnicas. A primeira é a mudança das fronteiras da tarefa no trabalho. Nessa técnica é alterado o conjunto de responsabilidades formais prescritas, adicionando ou excluindo tarefas, alterando a natureza das tarefas, ou realocando o tempo, energia e atenção utilizadas nas tarefas.

A segunda técnica é a mudança do limite relacional do trabalho, que pode ser através da qualidade ou quantidade das interações com os outros no trabalho, ou ambos. Essa técnica refere-se, então, à escolha sobre como, quando ou com quem se interage ao fazer o trabalho. Os relacionamentos de qualidade podem provocar atitudes de empenho e trabalho positivo. 
A terceira técnica é a alteração dos limites cognitivos do trabalho. Os limites cognitivos representam a forma como o funcionário vê o trabalho, se é como um conjunto de tarefas discretas no trabalho ou como um todo integrado. De acordo com Wrzesniewski e Dutton (2001), quando se muda o ponto de vista em relação ao trabalho, muda-se também a forma como os funcionários se aproximam dele.

\subsection{Modelo Job Demands-resources}

Ao mesmo tempo em que o conceito de job crafting era proposto, a primeira versão do modelo Job DemandsResources (JD-R) era desenvolvida com a finalidade de prever o burnout (Demerouti et al., 2001). Com o passar dos anos, esse modelo foi-se aprimorando e ganhando novas versões e aplicaçóes, que acabaram por maturá-lo em uma teoria (Bakker \& Demerouti, 2014). O modelo pressupõe que todas as ocupações laborais podem ter características específicas associadas ao bem-estar no trabalho, classificadas em demandas e recursos de trabalho, constituindo um modelo abrangente que pode ser aplicado a vários ambientes profissionais (Bakker \& Demerouti, 2005; 2007; 2016; Demerouti et al., 2001).

O modelo JD-R é composto por dois processos psicológicos que impactam profundamente o bem-estar dos empregados. O primeiro processo tem início quando as demandas de trabalho são elevadas e levam ao esgotamento, ou estado de exaustão do indivíduo. O segundo processo considera que os recursos de trabalho têm um potencial de motivação e engajamento e levam ao alto envolvimento no trabalho, baixo cinismo e melhora do desempenho. Esse potencial motivacional pode ser intrínseco, quando leva ao desenvolvimento e crescimento dos funcionários, e extrínseco, quando são responsáveis para alcançar metas de trabalho.

O modelo considera a interação entre os processos de motivação e desgaste no trabalho. Assim, os recursos de trabalho podem atenuar os efeitos negativos de altas demandas de trabalho. Dessa forma, um relacionamento de alta qualidade com um supervisor, autonomia, ou apoio de colegas, poderiam aliviar a sobrecarga de trabalho física e emocional e melhorar a relação com situações estressantes (Bakker \& Demerouti, 2007; 2016).

As demandas e recursos de trabalho referem-se a seus aspectos físicos, psicológicos, sociais ou organizacionais. As demandas podem ser caraterizadas por pressão no trabalho, ambiente físico e interações desfavoráveis com colegas, os quais exigem esforço ou habilidades físicas. Os recursos de trabalho são aspectos funcionais na realização de objetivos de trabalho e possuem potencial motivacional, que estimulam o crescimento pessoal, aprendizagem e desenvolvimento. Os recursos de trabalho satisfazem as necessidades psicológicas básicas do indivíduo, como autonomia, relacionamento e competência e podem ser localizados no nível da organização (salário, oportunidade de crescimento ou carreira, segurança), das relações interpessoais e sociais (participação em tomada de decisão) e da tarefa (habilidade, significância, feedback de desempenho, autonomia) (Bakker \& Demerouti, 2007; 2016).

A teoria JD-R faz a inclusão dos recursos pessoais no modelo, que têm efeito positivo sobre o engajamento de trabalho. Os recursos pessoais podem estar ligados à autonomia do indivíduo no trabalho, à resiliência, autoavaliações positivas, otimismo e autoconcordância, a qual motiva os indivíduos a perseguirem seus objetivos. Os recursos pessoais não são suficientes para atenuar a exaustão diante da alta demanda de trabalho, porém moderam a relação entre recursos de trabalho e engajamento, de modo que os recursos de trabalho podem desenvolver os recursos pessoais nos indivíduos.

Os recursos e demandas de trabalho têm efeitos únicos e multiplicativos sobre o estresse e motivação no trabalho. Além disso, a teoria trabalha com os efeitos de causa invertida entre demandas e estresse e entre o envolvimento e recursos. Assim, os níveis de exaustão e engajamento de trabalho também podem influenciar as demandas e recursos de trabalho, o que torna essa relação dinâmica. Dessa forma, os funcionários mais engajados são motivados a permanecer engajados e criar os seus próprios recursos de trabalho ao longo do tempo por meio do processo de job crafting. 
A teoria JD-R torna-se um ponto de partida para o estudo do job crafting, considerando que se refere a um processo de mudança que os empregados podem fazer para equilibrar suas demandas e recursos de trabalho com suas habilidades e necessidades pessoais (Tims et al., 2012). A partir da Figura 1 é possível identificar o processo motivacional - em destaque - e o de desgaste do trabalho no modelo JD-R, as relaçóes propostas por ele e a inclusão do job crafting no modelo.

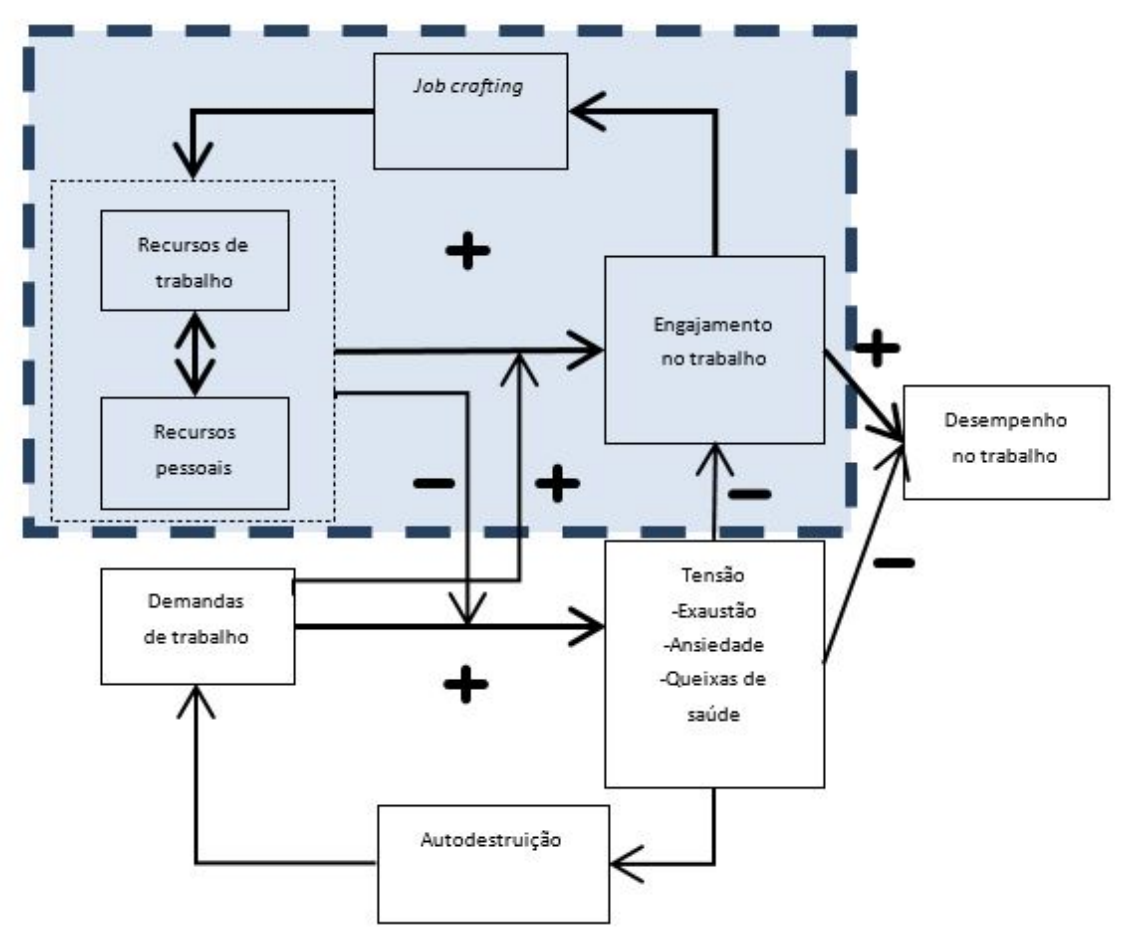

Figura 1 : Modelo JD-R - seus elementos e relações Fonte: Adaptado de Bakker e Demerouti (2014; 2016).

\subsection{Engajamento no trabalho}

O conceito de engajamento foi introduzido na literatura científica por Kahn (1990) para se referir aos indivíduos que possuem identificação com o trabalho e empenham-se mais nele, gerando um estado mental capaz de produzir resultados positivos no nível individual, como crescimento e desenvolvimento, e no nível organizacional, como desempenho.

O engajamento refere-se ao sentimento de realização ligado ao trabalho e é caracterizado por três fatores: vigor, dedicação e absorção (Schaufeli et al., 2002). O vigor é identificado por elevados níveis de energia, desejo de empenhar-se e perseverança frente às dificuldades do trabalho. Através do vigor as pessoas sentemse energizadas, fortalecidas, vibrantes, com elevada autoconfiança e encorajadas no trabalho. A dedicação é determinada pelo sentido de significado, entusiasmo, inspiração, orgulho e desafio no trabalho. A absorção é caracterizada pela compenetração, leveza e felicidade do indivíduo no trabalho, de forma que ele não perceba o decorrer do tempo durante o expediente de trabalho e não se impacta com as dificuldades a serem superadas nele.

Para a teoria JD-R, o engajamento tem uma relação benéfica com o comportamento de job crafting, pois funcionários engajados são mais suscetíveis a aumentar suas demandas e recursos de trabalho para melhorar o relacionamento social e criar um ambiente de trabalho desafiador. Dessa forma, o engajamento ocorre quando há um equilíbrio entre as demandas e os recursos de trabalho (Wingerden et al., 2017). Os resultados de estudo baseado no modelo JD-R na área pública brasileira demonstraram que, embora os servidores 
possuam os recursos de trabalho necessários e mesmo diante de baixa demanda de trabalho, o engajamento deles limita-se à dimensão dedicação (Santos, Costa, Freitas, \& Salles, 2019), não apresentando o vigor e a absorção.

Alguns fatores podem influenciar no engajamento dos funcionários. O clima organizacional quando é favorável, envolvente e desafiador, pode influenciar as percepções dos indivíduos quanto às demandas e recursos de trabalho e fomentar o engajamento (Bakker, Albrecht, \& Leiter, 2011). Outro aspecto importante que pode influenciar o engajamento no trabalho são as interações favoráveis entre membros e equipes onde são compartilhados emoções e comportamentos (Schaufeli, Dijkstra, \& Vazquez, 2013).

Os gestores podem influenciar positiva ou negativamente o engajamento e estado de humor de seus colaboradores. Ações injustas ou agressivas de um gestor podem despertar sentimentos negativos na equipe de trabalho. É importante que os empregadores construam um contexto organizacional no qual os funcionários sintam-se entusiasmados, energizados e motivados para propiciar o engajamento no trabalho (Bakker et al., 2011).

\subsection{Aspectos da Administração Pública relacionados ao trabalho}

Apesar da introdução de novos modelos de gestão de pessoas na Administração Pública, pesquisas indicam as dificuldades enfrentadas por diversos órgãos em pautar sua gestão em modelos realmente estratégicos (Avelino, Salles, \& Costa, 2017; Camões, Fonseca, \& Porto, 2010; Tribunal de Contas da União [TCU], 2013).

A falta de qualificação profissional dos responsáveis pelo desenvolvimento das políticas de RH, a falta de efetiva capacitação para os servidores, o foco exacerbado na atuação operacional em detrimento do foco estratégico, a ausência de mapeamento de competências e o pouco engajamento da alta administração nos assuntos relacionados à gestão de pessoal são fatores que levam a tentativas mal sucedidas na implementação de novas práticas na gestão de pessoas no setor público brasileiro (Avelino et al., 2017; Terabe \& Bergue, 2014). Além disso, as características centralizadoras e estruturas hierárquicas rígidas das organizações públicas evidenciam o alto controle de movimentação de pessoal dentro da lógica dos interesses políticos dominantes (Pires \& Macêdo, 2006).

Apesar de alguns dos princípios da administração pública gerencial pressuporem que os servidores tenham competência para autogestão e iniciativa, a Administração Pública brasileira ainda enfrenta desafios para a manifestação desses traços pelo conjunto do funcionalismo (Schickman, 2010). A estabilidade, a baixa autonomia (principalmente em níveis hierárquicos mais baixos), a falta de recursos materiais e humanos e a falta de recompensas associadas a desempenho geram descompromisso, desmotivação e insatisfação no trabalho. Essa situação acaba sobrecarregando aqueles que se interessam pelo trabalho e esperam se desenvolver com ele.

Por fim, outro aspecto que influencia o trabalho dos servidores é o fato de a remuneração e a estabilidade no emprego não serem consideradas suficientes para mantê-los motivados (Marconi, 2003; Vaitsman, 2001). Eles buscam um significado positivo no trabalho, que pode estar presente no companheirismo nas relações com colegas e chefias e na autonomia no desempenho de suas atribuições, de forma que consigam adaptar sua rotina de trabalho às suas preferências pessoais (Vaitsman, 2001).

\section{METODOLOGIA}

A pesquisa foi do tipo descritivo e com abordagem qualitativa. A escolha pela abordagem qualitativa está relacionada ao objetivo de melhor compreender a relação do job crafting com o engajamento no trabalho, um tema relativamente novo e pouco explorado no Brasil, especialmente no que tange à Administração Pública. 
A pesquisa foi realizada junto a 12 servidores técnico-administrativos selecionados por meio das estratégias de amostragem intencional e por acessibilidade. Buscou-se a multiplicidade de experiências relativa ao tempo de trabalho, ocupação ou não de cargos de chefia e atuação na área-fim ou na área-meio na instituição. A intenção de uma composição de grupo heterogênea objetivou a obtenção de dados diversificados em termos de concepções e percepção dos servidores, mas não houve a intenção de representar a unidade do CEFET Maria da Graça como um todo, ainda que ela contasse com apenas 33 servidores técnicoadministrativos em 2018. A escolha do CEFET/ RJ para realização da pesquisa deve-se ao fato de a instituição ser reconhecida pela qualidade do ensino ofertado em diversos níveis de formação, por encontrar-se num período de expansão devido à meta institucional de transformação do Centro em universidade tecnológica (Centro Federal de Educação Tecnológica Celso Suckow da Fonseca [CEFET/RJ], 2015), além do fato de uma das pesquisadoras ser funcionária da unidade Maria da Graça, permitindo acessibilidade a informações e potenciais participantes da pesquisa.

A escolha do tempo de trabalho dos participantes deve-se ao fato de que ele pode se refletir na proatividade e na criatividade no trabalho esperadas no comportamento de job crafting. Em relação à ocupação ou não de cargos de chefia, parte-se da premissa que estas duas categorias podem apresentar diferentes oportunidades para o comportamento de job crafting, principalmente relacionadas à autonomia que o cargo pode proporcionar. No que se refere às áreas de atuação, foram considerados os servidores atuantes das áreasfim e meio, visto que o nível de aproximação dos servidores com os alunos da instituição também pode refletir na motivação dos servidores em praticar o job crafting no trabalho.

Foi realizada a triangulação das fontes de evidências, utilizando-se informações de entrevistas semiestruturadas, técnica de complemento de frases, documentos e observação direta (Creswell, 2014). Assim, buscou-se a verificação ou corroboração de um determinado evento, descrição ou fato que está sendo relatado para o estudo, de forma a reforçar sua validade (Yin, 2015).

A coleta de dados de documentos públicos e internos foi realizada a partir de documentos institucionais relativos especialmente à gestão de pessoas. Foram também feitas anotações de campo sobre o comportamento e as atividades dos indivíduos no local da pesquisa, durante a realização das entrevistas.

$O$ roteiro de entrevistas semiestruturadas foi elaborado a partir da escala job crafting criada por Tims, Bakker e Derks (2012) para pesquisar o constructo baseado na teoria JD-R. As entrevistas foram gravadas e transcritas de maneira literal, perfazendo o total de 200 minutos. A partir da escala job crafting, são relacionados o aumento dos recursos estruturais do trabalho, a redução das demandas que são obstáculo ao trabalho, o aumento de demanda de trabalho desafiadora e o aumento de recursos sociais do trabalho. A escala job crafting foi adaptada baseada na instituição pesquisada e nas características do serviço público apresentadas nos aspectos teóricos da presente pesquisa.

O questionário para complemento de frases foi baseado em Santos, Costa, Freitas e Salles (2019) e preenchido pelos mesmos participantes entrevistados a fim de obter informações adicionais sobre os elementos do processo motivacional do modelo-teórico JD-R e os aspectos da administração pública que influenciam no comportamento dos servidores. O questionário foi composto por 34 frases evocadoras, associadas a dimensões propostas pelo modelo teórico JD-R e do job crafting (recursos, tarefas, relações no trabalho, aspectos cognitivos do trabalho e engajamento) e uma dimensão associada ao contexto da pesquisa (administração pública).

A fim de verificar a necessidade de ajustes ou aperfeiçoamentos nos instrumentos de coleta de dados, eles foram testados mediante a aplicação com dois servidores do CEFET Maria da Graça, antes da realização da pesquisa com os doze participantes.

$\mathrm{Na}$ análise e interpretação dos dados obtidos pelas entrevistas e técnica de complemento de frases, foi empregada a técnica de análise de conteúdo. A análise de conteúdo foi realizada seguindo as etapas estabelecidas por Bardin (1977): pré-análise, exploração do material e tratamento dos dados e interpretação. Essa análise foi realizada a partir de elaboração de uma grade fechada, considerando o contexto de trabalho 
na Administração Pública e com base nos elementos do processo motivacional do modelo conceitual JD$\mathrm{R}$, a saber: recursos, job crafting (alterações nas tarefas, nas relações no trabalho e nos aspectos cognitivos do trabalho) e engajamento de trabalho.

\section{RESULTADOS E DISCUSSÃO}

Como apontado, as entrevistas e questionário para complemento de frases objetivaram captar a percepção dos servidores acerca dos elementos do processo motivacional do modelo teórico JD-R. Além disso, foram relatadas as percepções dos servidores sobre os aspectos de trabalho na Administração Pública que podem influenciar na relação do job crafting com o engajamento no trabalho. É importante notar que em alguns momentos, esses mesmos elementos podem caracterizar vários eixos da pesquisa.

Apesar de certo receio em responder questões sobre o trabalho, nenhum servidor se negou a participar da pesquisa. Alguns sentiram-se muito confortáveis durante a entrevista e outros preocupavam-se com a forma que iam expor suas informações, com receio de não conseguirem falar utilizando linguagem apropriada. Algumas vezes, alguns servidores não compreendiam alguns termos estrangeiros utilizados na pesquisa, como "feedback". Alguns retornavam sempre em algum assunto que parecia ser de maior interesse para si mesmos.

A fim de segmentar os resultados, os participantes foram categorizados em termos de tempo de trabalho na Instituição, atuação ou não em cargos de chefia e área de atuação. Desse modo, o início do código de cada servidor é representado pela letra " $S$ " (servidor), seguida de um número de 1 a 12 , que indica a ordem da entrevista dele em relação às demais. As letras " $M$ " (meio) ou " $F$ ” (fim) correspondem à área de atuação dos servidores na unidade. Os servidores foram classificados em novos ou antigos pelas letras "N" ou "A", respectivamente. Foram considerados novos aqueles servidores com até cinco anos completos de atuação e os demais foram considerados antigos. Por último, a letra "C", quando houver, indica que o servidor é chefe. Assim, o participante 1, o primeiro entrevistado, é representado pelo código S1FA, trabalha na área fim, é antigo e não é chefe, como apresentado no Quadro 1.

Quadro 1: Participantes da pesquisa

\begin{tabular}{|c|c|c|c|c|c|c|c|}
\hline Participante & Chefe & Área & Cargo & Escolaridade & $\begin{array}{l}\text { Tempo no CEFET } \\
\text { (anos) }^{i}\end{array}$ & Sexo & Código de identificaçäo \\
\hline Servidora 2 & $\operatorname{Sim}$ & Meio & Administrador & Pos-graduaçäo & 3 & $\mathrm{~F}$ & S2MNC \\
\hline Servidor 3 & $\operatorname{Sim}$ & Meio & Administrador & Pós-graduaçäo & 4 & M & S3MNC \\
\hline Servidora 5 & Näo & Meio & Assistente em Administraçäo & Pós-graduaçäo & 4 & $\mathrm{~F}$ & SSMN \\
\hline Servidora 6 & Näo & Fim & Assistente em Administraçäo & Mestrado & 10 & $\mathrm{~F}$ & S6FA \\
\hline Servidor 7 & Nảo & Meio & Administrador & Mestrado em curso & 4 & M & S7MN \\
\hline Servidora 8 & Nảo & Fim & Auxiliar em Administraçăo & Graduaçäo & 2 & $\mathrm{~F}$ & S8FN \\
\hline Servidor 9 & $\operatorname{sim}$ & Meio & Assistente em Administraçäo & Nivel médio & $39^{*}$ & M & S9MAC \\
\hline Servidora 12 & Sim & Meio & Administradora & Poss-graduaçäo & 8 & $\mathrm{~F}$ & S12MAC \\
\hline
\end{tabular}

Fonte: Elaboração das autoras, a partir dos dados dos participantes. i: Tempo no CEFET/RJ, em anos, tomando-se como base o mês de janeiro de 2019.

* Tempo considerando os anos em que a instituição atuava antes da transformação em CEFET.

\subsection{Contexto de trabalho na Administração Pública}

As características específicas do ambiente de trabalho na esfera pública podem, a princípio, representar fatores limitadores ou facilitadores do comportamento do job crafting. Desta forma, em relação à legislação e 
regras presentes no serviço público, a maioria dos servidores considera que a partir delas é possível respaldar e padronizar suas atividades laborais. Os servidores consideram que alguns setores são mais amarrados à legislação que outros, mas muitas das regras existentes na Administração Pública podem ser flexibilizadas para tornar o ambiente de trabalho mais tranquilo. Esse fato está de acordo com os estudos de Vaitsman (2001), que considera que a inovação gerencial depende muito mais da forma que os dirigentes conduzem os processos produzidos pelas pessoas que pelas normas da instituição.

Alguns servidores têm receio de atuar de forma que possa ser questionada por órgãos de controle. $O$ fato vai ao encontro do que foi apontado por Wrzesniewski e Dutton (2001) no sentido de que algumas práticas que introduzem a inovação nas tarefas podem colocar a organização em risco devido a problemas legais. Assim, as regras burocráticas são vistas como algo próprio do serviço público e mesmo positivo, no sentido de dar respaldo ao servidor.

“Acredito muito que essas regras e rotinas, sendo negociadas, elas são vividas de maneira mais saudável . . . Eu não sou favorável a não ter regras, não é disso que eu tô falando. Acho que precisa ter, mas desde que essas regras sejam combinadas coletivamente e pra mim isso é importantíssimo, um diálogo" (S4FA).

"Às vezes é medo porque o servidor, ele fica muito desamparado... Então fica com medo de ter, de tomar uma, uma medida mais flexível e ser questionado por procurador, ou pela CGU [Controladoria Geral da União], ou por MP [Ministério Público]" (S7MN).

Um limitador importante para a inovação na gestão de pessoas na área pública, apontado por Terabe e Bergue (2014), é a falta de qualificação profissional dos responsáveis pelo desenvolvimento das políticas de recursos humanos. Os resultados encontrados reforçam esse aspecto. Os servidores sentemse "desamparados" pelo setor de RH; embora apontem que o setor esteja sempre disponibilizando cursos e treinamentos, os servidores consideram que as avaliações de desempenho individuais são realizadas de forma "fictícia", e os interesses e habilidades individuais dos servidores não são levados em consideração no momento de escolha do setor de lotação de cada um, provocando a desmotivação nos servidores. Essa percepção pode ser agravada pelo fato de o serviço ser centralizado na sede do CEFET.

Quando questionados sobre o impacto da estabilidade no trabalho, a maioria dos servidores acredita que ela aumenta a autonomia - aspecto importante para o comportamento do job crafting. Além disso, eles reconhecem que a luta para não se acomodar no trabalho deve partir deles mesmos e eles veem a estabilidade como algo negativo apenas quando se refere ao trabalho de alguns colegas, que acabaram se acomodando com o tempo no trabalho.

"Eu acho que a gente sempre fica numa situação mais confortável. Tem que ficar lutando também pra você não se acomodar, não perder o interesse, porque senão fica muito desagradável, né, você vir pra um lugar e não ter muito assim, muitas obrigações. E eu percebo que isso parte de mim, que não vem de ninguém” (S8FN).

Outro aspecto importante no contexto de trabalho do CEFET são os momentos de baixa demanda de trabalho. A maioria dos servidores sente-se insatisfeita com esses momentos e gostaria de poder atuar mais, mas a característica de sazonalidade das atividades escolares e a centralização de algumas funções na sede não permitem que os servidores executem determinadas tarefas.

"É muito complicado. É muito complicado você ver que tem serviço e você não ter o que fazer, não chegar pra você o trabalho que se tem" (S12MAC).

Os resultados dos complementos de frases apontaram que a maioria dos servidores, quando pensam no serviço público, lembra-se de estabilidade e burocracia. Poucos foram os momentos em que eles citaram a situação que o Brasil vem vivenciando - o que pode, talvez, ser explicado pelo relativo pouco tempo de atuação na instituição de boa parte dos entrevistados, que não teriam, então, uma vivência anterior que permita comparações. Apesar de os servidores verem as regras e a legislação como importantes para o trabalho, o termo "burocracia" representa uma conotação negativa para eles, de forma que eles a veem como algo negativo para 
o setor público. Além disso, os servidores apontaram que a dificuldade de inovar na área pública depende da própria vontade e das práticas institucionais.

\subsection{Recursos}

Em relação à autonomia de trabalho, a maioria dos servidores considera que ela existe, embora alguns fatores como dependência externa e legislação possam dificultá-la em alguns momentos. De acordo com Cullinane, Bosak, Flood e Demerouti (2017), a autonomia aumenta a percepção de oportunidades para o job crafting.

"Acho que só internamente né... porque assim, como tem essa questão da centralização ... O que eu tenho de autonomia pra fazer aqui são as questões da rotina interna do campus" (S2MNC).

No que se refere ao apoio da chefia, a maioria dos servidores tem percepções positivas. Apenas um servidor alegou que sua chefia inibe sua atuação, provocando sentimentos negativos nos funcionários (Schaufeli et al., 2013).

Em relação à aprendizagem e desenvolvimento, os servidores relataram que o CEFET disponibiliza muitos cursos e treinamentos a eles, porém, em alguns momentos, eles sentem falta de cursos voltados à sua área de interesse e da correta divulgação dos mesmos.

Quanto à remuneração recebida, foi possível levantar que nem sempre ela é percebida, pelos servidores, como fator associado à manutenção da motivação. Esse fato foi observado durante o relato de servidores que demonstraram desmotivação em assumirem cargos de chefia, quando as dificuldades inerentes ao cargo não compensam os benefícios proporcionados por eles. Esse resultado vem ao encontro do que foi apontado por Vaitsman (2001).

Em relação aos recursos pessoais, foi possível perceber que os servidores criam esses recursos de acordo com o contexto de trabalho, o que vem ao encontro do que foi apontado por Bakker e Demerouti (2014). Dessa forma, alguns tornam-se mais proativos quando conseguem alinhar o trabalho ao interesse pessoal e quando se sentem desafiados pelo trabalho, outros precisam dominar a resistência interior para tornaremse proativos.

"Isso é relativo né, porque isso depende muito do trabalho que você tá exercendo, onde você tá exercendo, com quem e dos momentos" (S11FA).

"Então eu tenho uma resistência, mas eu mesma tento quebrar isso, às vezes mais, às vezes menos. Se for uma coisa que eu domine um pouco mais, a resistência fica menor e aí pode ter uma proatividade maior” (S12MAC).

Em relação à capacidade e habilidades pessoais que os servidores participantes da pesquisa possuem, muitos deles acreditam que a instituição não permite que eles possam usá-las ao máximo, devido, principalmente a questóes burocráticas e à falta de incentivo da instituição. Um servidor que atua como chefe entende que a posição ocupada pelo cargo possibilita atuar de forma mais participativa. Esse fato pode refletir os efeitos atenuadores da autonomia nas demandas de trabalho (Bakker \& Demerouti, 2007, 2016).

Em relação ao questionário para complemento de frases, a maioria dos servidores considera ter um volume baixo de tarefas e um clima agradável no trabalho. Eles consideram que o envolvimento com colegas, a vontade de melhorar e a possibilidade de realizar projetos paralelos ao trabalho tornam o trabalho desafiador e aumenta a motivação, reforçando o aspecto da remuneração não se apresentar como fator destacado de motivação. Os servidores relataram sentir a autoestima e otimismo moderados ou de acordo com o contexto, o que reforça o apurado durante as entrevistas. A maioria deles sente falta de mudanças ou oportunidades para sentir-se mais animado no trabalho. No que se refere ao controle das suas tarefas, os servidores atuantes da área-fim sentem maior autonomia na execução de suas tarefas, enquanto os atuantes da área-meio sentem um controle maior da instituição, reforçando os aspectos apontados relativos à burocracia. 


\subsection{Job crafting - alteração nas tarefas}

Mesmo diante das limitações apontadas anteriormente, referentes à legislação e centralização de atividades na sede do CEFET, foi possível perceber que muitos servidores conseguem realizar adaptações em suas tarefas no sentido de alinhá-las às suas preferências e interesses, de modo a aumentar os recursos estruturais do trabalho (Tims et al., 2012). Em muitos casos, a limitação burocrática apontada pelos servidores refere-se não às legislações impostas por órgãos superiores, mas às regras impostas pela própria instituição. Essas limitações prejudicam o desenvolvimento dos servidores e da instituição.

Nesse sentido, os servidores consideram que existe alta interdependência entre as tarefas deles. Porém, essa interdependência interfere negativamente no trabalho e na autonomia deles apenas quando se refere à dependência de tarefas realizadas na unidade sede.

"A gente fica muito presa às limitações da própria instituição. Muita coisa é centralizada na sede. Daria uma autonomia melhor pra gente agir se fosse feito internamente no campus." (S2MNC).

Muitas vezes os servidores conseguem organizar e planejar suas tarefas de modo a não se concentrar durante um longo período em tarefas exaustivas. Dessa forma, eles reduzem demandas consideradas obstáculos no trabalho (Tims et al., 2012) a partir da distribuição das tarefas entre os membros da equipe para evitar sobrecarga de trabalho e desmotivação dos servidores. Algumas vezes, esse planejamento não é possível devido ao calendário escolar e às demandas esporádicas que podem vir de órgão superiores. No entanto, essa sazonalidade das atividades permite que eles se dediquem em projetos de seu interesse quando há baixa demanda de trabalho.

"Olha, uma estratégia são as reuniões de equipe, que a gente procura é, organizar o trabalho da própria equipe” (S4FA).

“Às vezes vêm diretrizes do próprio MEC [Ministério da Educação] com a data estipulada, e aí a gente tem que responder daqui a cinco dias. Mas depende muito" (S6FA).

A realização de novas tarefas propostas pela instituição poderia aumentar a demanda de trabalho desafiador pelos servidores, característica do job crafting. Porém, os servidores sentem-se entusiasmados com essas tarefas extras apenas quando são alinhadas aos seus interesses pessoais. Parte dos servidores não se sente estimulada a realizar essas mudanças na forma de trabalhar, no sentido de aproveitar as oportunidades para se desenvolver em diferentes áreas. Alguns servidores consideram que tarefas que exigem uma responsabilidade maior deveriam ser recompensadas de alguma forma, que poderia ser através de remuneração.

"Então, é... eu acho injusto. Eu acho que tarefas, certas tarefas, que até são de uma responsabilidade muito grande, eu acho que tem que ter algum tipo de motivação" (S5MN).

Em relação à forma que os servidores procuram se desenvolver no trabalho, alguns focam no seu próprio desenvolvimento e outros focam no seu trabalho do CEFET, referindo-se ao potencial motivacional intrínseco e extrínseco (Bakker \& Demerouti, 2007). Alguns servidores da área-fim algumas vezes conseguem conciliar o desenvolvimento profissional e pessoal a partir de cursos que atendam expectativas suas e da instituição. Esse resultado foi confirmado pelo questionário para complemento de frases.

Ainda segundo o questionário, os servidores revelaram que percebem oportunidade para o comportamento do job crafting diante de situações novas, dificuldades no trabalho e boas relações interpessoais. Nesse sentido, eles revelaram também que conseguem estimular seu desenvolvimento pessoal quando o trabalho faz sentido para si e para os envolvidos, realizam cursos e aprendem coisas novas. Essas mudanças provocam neles estados positivos como satisfação, motivação e sentimento de utilidade diante do trabalho.

Os dados coletados e as entrevistas evidenciaram que apenas dois dos entrevistados possuíam idade acima dos 40 anos e estes eram os únicos que não possuíam escolaridade acima dos exigido pelo cargo. Os demais 
procuraram qualificar-se com cursos que, embora permitissem a progressão salarial deles, acabavam por tornálos frustrados diante de um conhecimento que não poderia ser aplicado na prática no trabalho devido à burocracia interna da instituição. Isso pôde ser verificado, por exemplo, por meio de uma entrevista na qual um servidor com doutorado em andamento não podia atuar no campo de pesquisa e extensão. Além disso, alguns servidores relataram não utilizar sua capacidade e habilidades máximas devido a questóes culturais da instituição.

\subsection{Job crafting - alteração nas relações}

Segundo Berg, Dutton e Wrzesniewski (2013), os funcionários de uma organização podem realizar mudanças nas suas relações laborais de modo a aumentar o significado do trabalho.

O relacionamento entre os servidores foi considerado um dos principais aspectos responsáveis pela satisfação ou insatisfação deles no trabalho. O contato com colegas de maneira formal ou informal é sempre importante para manter a animação e a dedicação ao trabalho. Quando há problemas nas relações, o clima no trabalho torna-se mais desmotivador. Nesse sentido, alguns servidores veem maior problema nas relações quando se referem ao contato com a unidade sede.

“A parceria é grande, é muito boa. Agora, quando dependemos, que normalmente a gente depende externamente, pra fazer o nosso trabalho é que onde emocionalmente isso nos afeta, pelo menos me afeta, entendeu? Por problemas, dificuldades, deficiências que tem lá fora, que realmente atrapalham" (S5MN).

Alguns servidores reformulam relacionamentos existentes através de uma maior aproximação e envolvimento com os alunos. Nesse sentido, eles usam esse relacionamento para reduzir a intensidade emocional do seu trabalho mesmo recebendo críticas de colegas.

Todos os servidores participantes da pesquisa procuram cultivar relacionamentos existentes por meio da ajuda ou opinião de colegas, quando se refere a assuntos sobre os quais os demais possuem mais informações, o que vai ao encontro do que foi apontado por Wrzesniewski e Dutton (2001) no que se refere à necessidade de conexão humana para introduzir significado na vida dos indivíduos.

"Sempre que eu não sei alguma coisa eu não hesito em perguntar não, tanto ao chefe como lá na sede" (S6FA).

Alguns servidores, especialmente atuantes da área-fim aproveitam os momentos de reunião de equipe ou Avaliação de Desempenho Individual (ADI) para cultivar relacionamentos existentes, aumentando os recursos sociais do trabalho. Nesses momentos, os servidores conversam sobre o trabalho, buscam feedback dos colegas em relação ao seu desempenho e tomam decisões de forma conjunta, favorecendo a autonomia coletiva no trabalho. Outros servidores realizam o feedback de maneira mais informal.

"Então, a gente ao longo desses encontros com a equipe, a gente tenta definir as linhas de ação, definir quais são os projetos que a gente vai poder se dedicar de uma maneira mais intensa e outros que a gente talvez tenha que se organizar de outra forma... Esses encontros com a equipe né, esses encontros periódicos garantem que a gente consiga exercer e vivenciar essa autonomia” (S4FA).

Outro ponto importante percebido nas entrevistas foi que os servidores da área-fim possuem maior facilidade em identificar características positivas nos colegas e se inspirarem neles para trabalhar. Dessa maneira, eles se inspiram em aspectos éticos, respeito, dignidade, justiça e motivação enquanto os servidores da área-meio relataram basear-se em aspectos mais formais, ligados à produção e à organização no trabalho, não se referindo a colegas específicos.

Por meio do questionário de complemento de frases foi possível confirmar o relato nas entrevistas. Os servidores procuram relacionar-se com todos os colegas em situações informais ou de trabalho, possuem bom 
relacionamento com a chefia e procuram melhorar o ambiente de trabalho através do diálogo e do respeito, evitando conflitos desnecessários.

\subsection{Job crafting - alteração nos aspectos cognitivos do trabalho}

A escala genérica do job crafting proposta por Tims et al. (2012) não inclui a dimensão da alteração dos limites dos aspectos cognitivos do trabalho. Porém, durante as entrevistas foram observados relatos dos servidores, especialmente daqueles atuantes da área fim da instituição, que se comportam de acordo com essa técnica do job crafting. Nesse sentido, um servidor relatou conseguir reduzir a intensidade emocional do trabalho quando se dedica por completo em casos de estudantes, que refletem a sua atuação nos resultados finais da escola. Desta forma, ele estaria focando percepções, que de acordo com Berg et al. (2013), significa estreitar o alcance mental do propósito do seu trabalho.

"Eu, de fato, hoje, talvez eu consiga analisar melhor, ter uma leitura mais criteriosa, mais crítica, porque realmente eu me entrego em algumas situações, né, principalmente quando são casos que envolvem estudantes e famílias, a escola como um todo" (S4FA).

Outro servidor, atuante da área-meio, procura desenvolver-se e aprender coisas novas no trabalho quando se comunica com outros colegas, especialmente com aqueles da área-fim, para testar novas práticas voltadas para um contexto maior. Esse comportamento está de acordo com a mudança cognitiva no sentido de desenhar conexões mentais entre o relacionamento com os colegas e conhecimento de necessidades da escola como um todo (Berg et al., 2013).

"Uma ferramenta básica, que é comunicar com outros colegas, tanto daqui quanto de outros setores, quanto da área acadêmica, pra entender também, porque a função principal do colégio tá voltada pra área acadêmica, pra ver quais as práticas que eles estão implementando que possam dar certo aqui” (S7MN).

Um dos servidores procura o seu crescimento pessoal ao mesmo tempo em que contribui para o objetivo maior da instituição, através do incentivo à leitura pelos alunos no setor da biblioteca. Dessa forma, ele altera os aspectos cognitivos de modo a expandir sua percepção acerca do alcance mental do seu trabalho (Berg et al., 2013) para, assim, trabalhar mais satisfeito:

"Não é só um lugar pra chegar aqui e pegar o livro só ... Dentro da biblioteca você lê, e você crescer como pessoa, você tá contribuindo para o crescimento da biblioteca, porque um lugar de leitura, ao entrar um aluno e ver que você está lendo, né, tem tudo a ver com o ambiente" (S11FA).

Os resultados dos questionários para complemento de frases apontaram que os servidores conseguem perceber a importância de seu trabalho principalmente quando os colegas sentem sua falta ou quando recebem elogios, o que demonstra a relevância das relações no trabalho. Quando pensam no trabalho, os servidores se veem privilegiados, realizados e integrantes de um todo maior, mas quando os servidores pensam no CEFET, veem o trabalho como algo burocrático e não reconhecido. Essa diferença nas respostas demonstra que os servidores têm uma visão negativa da instituição, possivelmente devido às dificuldades relacionadas à centralização e profusão de regras da instituição. Ainda assim, conseguem perceber a importância do trabalho quando pensam no que o CEFET oferece à sociedade e eles esperam que o trabalho proporcione tanto o crescimento pessoal deles como o institucional.

\subsection{Engajamento no trabalho: dedicação, vigor e absorção}

Baseado nos relatos dos itens anteriores e de acordo com as dimensões do engajamento no trabalho propostas por Schaufeli et al. (2002), foi percebido que muitos servidores apresentam a dimensão dedicação 
do engajamento no trabalho. Essa dimensão foi identificada quando os servidores relataram perceber o significado e utilidade do seu trabalho para os alunos e para a escola, de modo que sentem orgulho e se entregam por completo. Nesse sentido, foi possível identificar que a maioria dos servidores gosta e se entrega ao trabalho que executa. Em relação à dimensão absorção do engajamento no trabalho, os servidores relataram que se sentem absorvidos por ele, de forma que não gostam dos momentos que não conseguem desempenhar suas tarefas, pois percebem que a demanda de trabalho existe e sentem-se bem quando estão realizando suas atividades.

No entanto, em muitos momentos faltam energia e entusiasmo no trabalho dos servidores para realizar suas tarefas, que caracterizam a dimensão vigor do engajamento no trabalho. Isso foi observado no fato de alguns servidores não se sentirem motivados nem pelas recompensas provenientes da ocupação de cargos de chefia, na centralização, profusão de regras internas, falta de comunicação adequada em relação à unidade sede e na dificuldade de organizar e planejar suas tarefas devido a algumas questões que fogem de seu controle. Além disso, o fato de alguns servidores considerarem suas tarefas simples faz com que o trabalho não apresente grandes desafios para eles. Dessa forma, os servidores muitas vezes não conseguem utilizar suas capacidades e conhecimentos ao máximo, gerando sentimento de frustração e não reconhecimento pela instituição. Esses resultados vão ao encontro do apresentado por Santos et al. (2019) na unidade sede do CEFET/RJ.

Nos resultados dos complementos de frases os servidores revelaram, em relação à dedicação, que a realização de projetos que alinham seu trabalho a interesses pessoais, as relações no trabalho e as demandas de trabalho desafiadoras podem ser considerados meios para se alcançar a dedicação no trabalho e o ambiente de trabalho do CEFET Campus Maria da Graça favorece essas ações. Em relação à maneira como se sentem quando pensam no trabalho, os servidores atuantes da área-fim revelaram-se mais satisfeitos e com vontade de melhorar quando comparado aos atuantes na área-meio. Em relação à dimensão vigor, que representa a energia em trabalhar, a maioria dos servidores sente-se desmotivado e frustrado na hora de ir para o trabalho e quando pensam nas dificuldades que o trabalho apresenta. Em relação à dimensão absorção do engajamento no trabalho, os servidores revelaram concentrar-se para executar suas funções da melhor forma possível e que o tempo passa rápido durante suas atividades laborais. As respostas dos complementos de frases vão ao encontro do que foi relatado nas entrevistas.

Além disso, os servidores revelaram que quando se sentem engajados, ficam mais satisfeitos e enxergam soluções sendo criadas, o que demonstra os efeitos de causa invertida entre o engajamento no trabalho e o job crafting, o que pode acarretar efeitos multiplicativos do constructo.

\section{CONSIDERAÇÕES FINAIS}

O objetivo principal deste estudo foi descrever a relação entre o processo de job crafting e o engajamento no trabalho dos servidores técnico-administrativos (TAEs) do Campus Maria da Graça do CEFET/ RJ, com base no modelo teórico JD-R. Para isso, buscou-se descrever os elementos que compóem o processo motivacional do modelo JD-R, como os recursos de trabalho e recursos pessoais, as técnicas do job crafting - alteração dos limites das tarefas, das relações e dos aspectos cognitivos de trabalho e o engajamento no trabalho. Também foram descritas características específicas da Administração Pública presentes na instituição pesquisada que poderiam influenciar esse tipo de comportamento dentro das atribuições do trabalho.

Os resultados apontam que o grupo de servidores participantes da pesquisa entende possuir os recursos pessoais e de trabalho necessários, possuir baixa demanda de trabalho e procurar realizar alterações nas suas tarefas, relacionamentos e aspectos cognitivos do trabalho. Porém, essas alterações melhoram o engajamento do trabalho apenas nas dimensões da absorção e dedicação ao trabalho. Os servidores não apresentam elevados níveis de energia e perseverança frente às dificuldades de trabalho que caracterizam a dimensão vigor do engajamento no trabalho. A profusão de regras internas, centralização das principais atividades da 
instituição na unidade sede e sazonalidade das funções da escola podem influenciar na ausência do vigor no trabalho. É importante ressaltar que essa profusão de regras internas da instituição tem um impacto mais negativo na relação do de job crafting e engajamento de trabalho do que a própria legislação e rotina de trabalho no serviço público.

Outro ponto que deve ser notado é que os servidores atuantes da área-fim são mais propensos a procurar melhorar o engajamento através do job crafting por meio de reunióes com a equipe, maior facilidade a associar o trabalho a interesses pessoais e maior possibilidade de enxergar seu trabalho como parte de um todo integrado. Cabe destacar que o trabalho realizado pelos servidores atuantes nas atividades-fim apresenta mais elementos que favorecem a motivação como autonomia, feedback e significância das tarefas, como apontado por Hackman e Oldham (1980). Isso pode explicar, ao menos em parte, as diferentes percepções dos servidores em relação ao job crafting.

As entrevistas apontam que, embora a instituição apoie, promova e facilite a capacitação dos servidores, a formação nem sempre se traduz em maior realização no trabalho e melhor desempenho. Dessa forma, foi observado que apesar de os servidores possuírem esses recursos de trabalho que a própria instituição oferece, eles não conseguem realizar o job crafting, muitas vezes devido a questões relacionadas às relações políticas internas, hierarquia e estrutura organizacional da própria instituição. Isso pôde ser verificado diante das dificuldades apontadas pelos servidores na relação deles com o setor de recursos humanos e a centralização de atividades na unidade sede.

É interessante notar que os resultados demonstraram que a atual crise econômica que o Brasil vem vivenciando e a meta institucional de transformação do CEFET em Universidade Tecnológica não têm impacto negativo nas mudanças que os servidores realizam no seu modo de trabalhar. De modo contrário, os relacionamentos interpessoais tiveram destaque nos relatos de modo a influenciar o comportamento de job crafting dos servidores em vários aspectos.

Pode-se concluir ainda, a partir das evidências, que há ocorrência do processo de job crafting por meio dos efeitos de causa invertida e dos efeitos multiplicativos do constructo. Desta forma, a realização de projetos que alinham o trabalho dos servidores a interesses pessoais, as relaçóes no trabalho e as demandas de trabalho desafiadoras podem ser considerados meios para se alcançar a dedicação no trabalho. Então, os servidores se engajam mais no trabalho quando há possibilidade de praticar o job crafting, criando os recursos para trabalharem mais e satisfeitos e assim tornam-se ainda mais engajados no trabalho.

Embora este estudo possa ter sido passível de imprecisão ou vieses por parte dos respondentes, é importante destacar que seu objetivo foi o de descrever as percepções dos servidores frente aos elementos do modelo JDR e não diagnosticar a instituição CEFET/RJ. Sugere-se, por fim, que novos estudos sejam realizados sobre o tema, a fim de aprofundar o entendimento sobre a relação do processo do job crafting com o engajamento no trabalho.

\section{REFERÊNCIAS}

Avelino, K, Salles, D., Costa, I. (2017). Collective competencies and strategic people management: a study carried out in federal public organizations. Revista de Administrac\#a\#o Mackenzie, 18(5), 202-228.

Bakker, A. (2015). A job demands-resources approach to public service motivation. Public Administration Review, $75(5), 723-732$.

Bakker, A., Albrecht, S., Leiter, M. (2011). Work engagement: Further reflections on the state of play. European Journal of Work and Organizational Psychology, 20(1), 74-88.

Bakker, A., Demerouti, E. (2007). The job demands-resources model: State of the art. Journal of Managerial Psychology, 22(3), 309-328.

Bakker, A., Demerouti, E. (2014). Job Demands-Resources Theory. In: Chen, P., \& Cooper, C. (Eds.). Work and wellbeing: a complete reference guide. John Wiley \& Sons, Ltd. Vol.3. 
Bakker, A., Demerouti, E. (2016). Job Demands-Resources Theory: Taking stock and looking forward. Journal of Occupational Health Psychology, 22(3), 273-285.

Bardin, L. (1977). Análise de conteúdo. Lisboa: Edições 70.

Berg, J., Dutton, J., Wrzesniewski, A. (2013). Job crafting and meaningful work. In: Dik, B., Byrne, Z., \& Steger, M. (Eds.). Purpose and meaning in the workplace. Washington, DC: American Psychological Association.

Boon, C., Eckardt, R., Lepak, D., Boselie, P. (2018). Integrating strategic human capital and strategic human resource management. The International Journal of Human Resource Management, 29(1), 34-67.

Camões, M., Fonseca, D., Porto, V. (Org.). Estudos em gestão de pessoas no serviço público. Brasília: ENAP.

Centro Federal de Educação Tecnológica Celso Suckow da Fonseca. (2015). Plano de Desenvolvimento Institucional 2015-2019. Rio de Janeiro: CEFET/RJ. Recuperado em 8, jan., 2019, de http://www.cefet-rj.br/attachments/ article/97/PDI\%202015-2019_versa\%CC\%83o\%20final\%20revisada\%20(2).pdf.

Cullinane, S., Bosak, J., Flood, P., Demerouti, E. (2017). Job crafting for lean engagement\#: The interplay of day and job-level characteristics. European Journal of Work and Organizational Psychology, 26(4), 1-14.

Creswell, J. W. (2014). Investigação qualitativa e projetos de pesquisa. Porto Alegre: Penso.

Devotto, R., Machado, W. (2017). Job crafting: uma revisão da produção científica internacional. Psico-USF, 22(3), 413-423.

Garcia, L. (2014). Competências transversais e percepção de suporte à aprendizagem na SBQ/ANP - Agência Nacional do Petróleo. In M.Camões, D., Fonseca, \& V. Porto. (Org.).Estudos em gestão de pessoas no serviço público. Brasília: ENAP.

Hackman, J.; Oldham, G. (1980). Work redesign. Reading: Addison-Wesley.

Longo, F. (2007). Mérito e flexibilidade: a gestão das pessoas no setor público. São Paulo: Fundap.

Kahn, W. (1990). Psychological conditions of personal engagement and disengagement at work. Academy of Management Journal, 33(4), 692-724.

Mancebo, D. Crise político-econômica no Brasil: breve análise da educação superior (2017). Educação \& Sociedade, $38(141), 875-892$.

Mancebo, D., Silva, J. Júnior, Oliveira, J. (2018). Políticas, gestão e direito a educação superior: novos modos de regulação e tendências em construção. Acta Scientiarum, 40(1) 1-11.

Marconi, N. (2003). A evolução do perfil da força de trabalho e das remunerações nos setores público e privado ao longo da década de 1990. Rev. do Serv. Público, 54(1), 9-45.

Pires, J., Macêdo; K. (2006). Cultura organizacional em organizações públicas no Brasil. Revista de Administração Pública, 40(1), 81-105.

Santos, S., Costa, I., Freitas, J., Salles, D. (2019). Percepções de engajamento no trabalho sob a ótica do modelo JD-R: estudo em um Centro Federal de Educação Tecnológica no Rio de Janeiro. Organizações em Contexto, 15(30), 121-158.

Schaufeli, W., Dijkstra, P., Vazquez, A. (2013). Engajamento no trabalho. São Paulo: Casa do Psicólogo.

Schikmann, R. (2010). Gestão estratégica de pessoas: bases para a concepça\#o do curso de especializac\#a\#o em gesta\#o de pessoas no servic\#o pu\#blico. In M. Pantoja, M. Camo\#es, \& S. Bergue (Orgs.). Gesta\#o de pessoas: bases teo\#ricas e experie\#ncias no setor pu\#blico. Brasi\#lia: ENAP.

Terabe, C., Bergue, S. (2010). Gestão estratégica de pessoas como política pública: estudo de caso no Ministério da Ciência, Tecnologia e Inovação. In M. Camões, D. Fonseca, \& V. Porto. (Org.). Estudos em gestão de pessoas no serviço público. Brasília: ENAP.

Tims, M.; Bakker, A. B.; Derks, D. (2012). Development and validation of the job crafting scale. Journal of Vocational Behavior, 80(1), 173-186.

Tribunal de Contas da União. (2013). Levantamento de governança e gestão de pessoas. Brasília.

Tuan, L. (2017). HR flexibility and job crafting in public organizations: the roles of knowledge sharing and public service motivation. Group\& Organization Management, 44(3), 549-577. 
Vaitsman, J. (2001). Gerencialismo, cultura e expectativas entre servidores públicos de saúde. Revista de Administração Pública, (35) 1, 29-47.

Wingerden, J., Bakker, A., Derks, D. (2017). The impact of personal resources and job crafting interventions on work engagement and performance. Human Resource Management, 56(1), 51-67.

World Economic Forum (2018). What's the future of human resources? Geneva. Recuperado em 11, mar., 2019 de h ttp://www3.weforum.org/docs/WEF_Future_of_Jobs_2018.pdf.

Wrzesniewski, A., Dutton, J.E. (2001). Crafting a job: revisioning employees as active crafters of their work. Academyof Management Review, 26(2), 179-201.

Yin, R. (2015). Estudo de caso: planejamento e métodos. 5. ed. Porto Alegre: Bookman. 